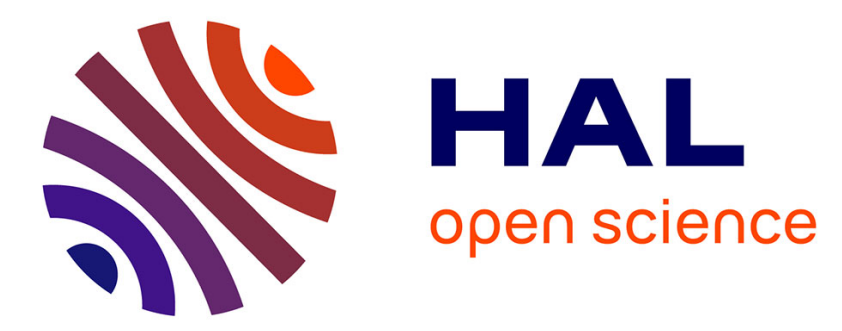

\title{
Management of epi- and mesotympanic cholesteatomas by one-stage trans-canal atticotomy in adults
}

Daniele Bernardeschi, Francesca Yoshie Russo, Yann Nguyen, Giuseppina Canu, Isabelle Mosnier, Daniele de Seta, Evelyne Ferrary, Olivier Sterkers

\section{- To cite this version:}

Daniele Bernardeschi, Francesca Yoshie Russo, Yann Nguyen, Giuseppina Canu, Isabelle Mosnier, et al.. Management of epi- and mesotympanic cholesteatomas by one-stage trans-canal atticotomy in adults. European Archives of Oto-Rhino-Laryngology, 2016, 273 (10), pp.2941-2946. 10.1007/s00405015-3875-3 . hal-01255052

\section{HAL Id: hal-01255052 https://hal.sorbonne-universite.fr/hal-01255052}

Submitted on 13 Jan 2016

HAL is a multi-disciplinary open access archive for the deposit and dissemination of scientific research documents, whether they are published or not. The documents may come from teaching and research institutions in France or abroad, or from public or private research centers.
L'archive ouverte pluridisciplinaire HAL, est destinée au dépôt et à la diffusion de documents scientifiques de niveau recherche, publiés ou non, émanant des établissements d'enseignement et de recherche français ou étrangers, des laboratoires publics ou privés. 
MANAGEMENT OF EPI- AND MESOTYMPANIC CHOLESTEATOMAS BY ONESTAGE TRANS-CANAL ATTICOTOMY IN ADULTS

Daniele Bernardeschi MD PhD ${ }^{1,2,3}$, Francesca Yoshie Russo MD ${ }^{1,2,3}$, Yann Nguyen MD PhD ${ }^{1,2,3}$ ,Giuseppina Canu MD ${ }^{4}$, Isabelle Mosnier $\mathrm{MD}^{1,2,3}$, Daniele De Seta $\mathrm{MD}^{1,2,3}$, Evelyne Ferrary MD $\mathrm{PhD}^{1,2,3}$ and Olivier Sterkers MD $\mathrm{PhD}^{1,2,3}$

1. AP-HP, Pitié-Salpêtrière Hospital, Department of Otology, Auditory Implants and Skull Base Surgery, F-75013, Paris, France

2. Sorbonne University, UPMC Univ Paris 06, F-75005, Paris, France

3. Inserm UMR-S 1159, «Minimally invasive robot-based hearing rehabilitation», F-75018, Paris, France

4. University of Parma, Department of clinical and experimental medicine, Parma, Italy

\section{Corresponding author:}

Daniele Bernardeschi, MD, PhD

Department of Otology, Auditory Implants and Skull Base Surgery

Pitié-Salpêtrière Hospital 50/52 Bd Vincent Auriol

75013 - Paris - France

Tel: +33(0)142162603

Fax : + $33(0) 142162605$

E-mail : daniele.bernardeschi@aphp.fr 


\section{ABSTRACT}

Surgical management of cholesteatoma limited to the attic and/or mesotympanum remains controversial. The aim of this study is to evaluate the anatomical and the functional results of trans-canal atticotomy in this pathological condition. The records of 27 adult patients treated from 2008 to 2014 who underwent trans-canal atticotomy for primary cholesteatoma surgery were reviewed. Preoperative physical examination, audiometry, and CT-scan have been analyzed. Intraoperative findings have been described as well as the surgical technique. Anatomical and functional results have been evaluated with a mean follow up of $24 \pm 12.2$ months, and the results of a CT-scan performed 1 year after surgery were examined to assess the presence of residual disease. Surgeries were uneventful. During the follow-up, 1 patient (4\%) experienced a retraction of the attical reconstruction; all the other patients had a wellhealed tympanic drum with stable attical reconstruction. The mean air-bone gap was $19 \pm$ $12.2 \mathrm{~dB}$ and $10 \pm 7.3 \mathrm{~dB}$ pre-operatively and post-operatively, respectively (mean $\pm \mathrm{SD}$, $\mathrm{p}=0.001$, paired t-test). Twenty-two patients $(81 \%)$ had no opacity suggesting residual cholesteatoma in CT-scan. Four patients $(15 \%)$ presenting an opacity at CT-scan underwent MRI study that was negative for residual cholesteatoma. One patient (4\%) had displacement of the ossicular prosthesis.

In conclusion, cholesteatomas restricted to the attic and/or mesotympanum can be removed in a one-stage technique with no visible residual at 1 year, and with closure of the air-bone gap by $50 \%$.

Keywords: cholesteatoma, atticotomy, canal-wall-up, mastoidectomy, facial nerve, chronic otitis. 


\section{INTRODUCTION}

The aim of cholesteatoma surgery is to eradicate the disease avoiding the residual, preventing the recurrence and restoring or preserving the hearing.

Two main procedures have been developed to achieve these goals: the canal-wall-up (CWU) and the canal-wall-down (CWD) tympano-mastoidectomy. Each procedure has its own advantages and disadvantages: the CWU is said to have better functional results whereas the CWD is related to lower incident of residual/recurrent disease. The former needs in most of the cases a second look to restore hearing. The latter is often related to cavity problems like intermittent otorrhea, difficulty of fitting a hearing aid if necessary, and vertigo due to thermic stimulation of the posterior labyrinth. In order to reduce these cavity-related consequences, obliteration techniques might be proposed.

In the literature, there is not a consensus regarding the optimal treatment of cholesteatomas limited to the attic or mesotympanum. While some authors advocate the necessity of a CWD procedures even in case of limited lateral epitympanic cholesteatoma with intact ossicular chain [1], others are more conservative using the atticotomy [2] or CWU technique [3], especially in children [4]. Recently the use of full endoscopic procedures has been proposed for these limited cholesteatomas [5,6].

The aim of this study was to describe our technique of one-stage trans-canal atticotomy (TA) for cholesteatomas limited to the attic and mesotympanum, and to analyze the complications, and the functional and anatomical results. 


\section{MATERIALS AND METHODS}

The clinical reports of twenty-seven patients (27 ears) out of 238 surgically treated for cholesteatoma in a tertiary referral center (11\%) between 2008 and 2014, have been included in this retrospective study. The inclusion criteria were the presence of primary cholesteatoma of attic and/or mesotympanum treated with a one-stage TA. All the other cases of cholesteatoma with antral or mastoid invasion were excluded. All patients gave their informed consent to the use of their clinical data.

Values are expressed as means $\pm \mathrm{SD}$. Hearing results were compared using paired $t$ test. $\mathrm{P}<$ 0.05 was considered statistically significant.

\section{RESULTS}

There were 10 males and 17 females (Table 1). The mean age was $45 \pm 16$ years (range 17/72 years). There were 14 right-side and 13 left-side cases. All cases were primary surgeries; there was no recurrent or residual disease in this series.

All patients underwent preoperative physical examination though microscopic otoscopy, puretone audiometry in a sound-treated room [pure-tone averages (PTA) for bone conduction (BC) and air conduction (AC) were calculated as the mean of 500-, 1000-, 2000-, 3000-Hz thresholds], and high resolution CT-scan imaging.

Surgeries were performed under general anesthesia. Facial nerve monitoring system NIM ${ }^{\circledR} 2$

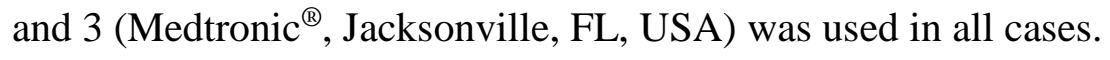

A retroauricolar skin incision with elevation of anterior C-shaped muscolo-periosteal flap was performed after infiltration with adrenaline solution $(1 \mathrm{mg} / 15 \mathrm{ml})$ in the retroauricolar region 
and in the external auditory meatus (EAM). Temporalis fascia and cymba/cavum conchae cartilage was harvested. Cartilage was then thinned using Precise Cartilage Knife (KURZ ${ }^{\circledR}$, Tubingen, Germany).

Incision of the skin of the EAM was performed using an 11-blade knife. Then a superior incision (at 9 o'clock) and an inferior incision (at 6 o'clock) were performed and the tympanomeatal flap was raised until the anulus (Figure 1). The middle ear was entered at 6 o'clock and the elevation of the anulus proceeded postero-superiorly. If a mesotympanic cholesteatoma was present, the cholesteatoma pocket was cut and the elevation of the tympanomeatal flap was performed superiorly to isolate the epitympanic cholesteatoma. Thereafter, the attical cholesteatoma pocket was cut and the tympanic drum was detached from the malleus handle in order to isolate completely the healthy tympanomeatal flap from cholesteatoma pockets (Figure 2).

The isolated tympanomeatal flap was protected with a silastic sheet and a TA was performed with $3 \mathrm{~mm}$ diamond burr. The cholesteatoma pocket was followed posteriorly and anteriorly, until the posterior and anterior limits were reached. If a mesotympanic cholesteatoma was present (Figure 3a), the removal of the pathology was performed after having drilled the postero-superior part of the scutum. After the cholesteatoma removal, when necessary an endoscopic look to the sinus tympani and the posterior epitympanum was performed using a $30 \% \mathrm{~mm}$ endoscope (Figure 4). In case of limited lateral epitympanic cholesteatoma with an intact ossicular chain (Figure 3b), reconstruction started after cholesteatoma removal without disrupting the ossicular chain: in these cases, the reconstruction was performed using temporalis fascia and thinned cartilage over the malleus handle in order to reconstruct both the tympanic drum and the lateral wall of the attic. 
If the ossicular chain was interrupted, and/or if the ossicles were invaded/eroded by cholesteatoma, and/or if there was an extension of the cholesteatoma medial to the ossicular chain (figure 3c), malleus and incus were removed. Columellar effect was restored after cholesteatoma removal using $\mathrm{KURZ}^{\circledR}$ Arial partial or total ossicular replacement prosthesis depending if the stapedial arch was present or not. Then the reconstruction using fascia and cartilage was performed as mentioned above. Even in case of intact pars tensa and cholesteatoma limited to the attic, the tympanic drum was always reinforced with thinned cartilage

All patients underwent physical examination with otomicroscopy and PTA at 1 month and at 1 year, and CT-scan at 1 year. If any opacity was detected at the CT-scan, a diffusion MRI study was performed.

The mean follow-up (FU) was $24 \pm 12.2$ months (range 13/54 months).

\section{Pre-operative data}

The microscopic examination of the pars tensa showed a normal tympanic drum in 13 cases (48\%), a postero-superior retraction pockets in 7 cases (26\%), a tympanic drum perforation in 5 cases $(19 \%)$, and cholesteatoma in 2 cases $(7 \%)$. Concerning the pars flaccida, there was a retraction pocket with or without evident aspects of cholesteatoma in 23 cases (86\%), an inflammatory polyp was found in 2 cases (7\%), and it was normal in 2 cases (7\%).

The mean AC PTA was $38 \pm 16 \mathrm{~dB}$, the mean BC PTA was $19 \pm 8.8 \mathrm{~dB}$. The mean air-bone gap $(\mathrm{ABG})$ was $19 \pm 12.2 \mathrm{~dB}$.

Pre-operative imaging showed opacity in the mesotympanum in 15 cases (55\%). In the attic, an isolated lateral opacity was found in 10 cases (37\%), a medial isolated opacity in 1 case 
(4\%), and an opacity involving the entire attic in 11 cases (41\%). Five cases (18\%) presented no opacity.

No dehiscence of the tegmen epitympanum or fistula of the lateral semicircular canal was noted in this series. Two patients had pre-operative MRI that was positive for cholesteatoma.

\section{Surgical findings}

Cholesteatoma occupying the mesotympanum was found intra-operatively in 16 ears (59\%); regarding the epitympanum, a lateral cholesteatoma was found in 15 cases (55\%), a cholesteatoma involving the entire attic in 12 cases (45\%).

The ossicular chain was preserved intact in 4 cases $(15 \%)$; in all the other cases, the incus and the malleus were removed, and the ossicular chain reconstruction was performed with partial ossicular replacement prosthesis in 15 cases (55\%), and a total ossicular replacement prosthesis was realized in 8 cases $(30 \%)$.

\section{Post-operative results}

All but 1 patient presented during the last FU a well-healed tympanic drum with a stable attical reconstruction, without any sign of retraction. This patient (4\%) experienced retraction of the cartilage used for the reconstruction of the atticotomy but the reconstruction was still self-cleaning with good hearing result and no post-operative opacity on CT-scan (patient 25).

\section{Audiological results}

The mean AC PTA was $31 \pm 14.4 \mathrm{~dB}$, the mean BC PTA was $21 \pm 12.6 \mathrm{~dB}$. The mean ABG was $10 \pm 7.3 \mathrm{~dB}$. The difference with the preoperative outcomes was statistically significant $(\mathrm{p}=0.001)$. Specific audiological results related to ossicular chain reconstruction are detailed 
in tab. 2. The mean hearing gain was $8 \pm 4.9 \mathrm{~dB}$ for type 1 tympanoplasty (NS), $6 \pm 12.3 \mathrm{~dB}$ (NS) for type $2,15 \pm 13.7 \mathrm{~dB}(\mathrm{p}=0.004)$ for type 3 .

\section{Post-operative imaging}

In 22 cases (81\%) a well-aerated middle ear and epitympanum was found without any opacity suggesting a residual cholesteatoma (Figure 5). In one case (4\%) the ossicular prosthesis was found displaced (patient 19, type 3 tympanoplasty). In 4 cases (15\%) attical or mesotympanic opacity was found, but the MRI study was negative for residual cholesteatoma showing only inflammatory fluid in these areas (Table 1). 


\section{DISCUSSION}

The surgical management of cholesteatoma limited to the epitympanum and/or mesotympanum still remains controversial. TA was firstly described in 1974 by Donald et al [2] in the USA and in Europe by Wullstein [7] in the same year; the first described a drilling procedure of the superior wall of the attic with reconstruction with silastic and temporalis fascia; the latter performed a trephination of the lateral epitympanic wall with removal of a bony lid and its further replacement after having removed the cholesteatoma.

Since then, very few reports have been realized concerning this surgical technique: in 1998 East [8] published on 65 patients treated with atticotomy followed by reconstruction of the defect with cartilage. Regarding anatomical results, he found 3\% of recurrence but nothing was said about residual. In 2002 Duckert et al [9] published on 34 adults and 11 children treated with trans-canal atticotomy but they included also posterior extension in the mastoid. The reconstruction was achieved with a composite cartilage/perichondrial graft and pedicle postauricular perichondrial flap. Regarding anatomical results, they had $11 \%$ of recurrence and near $50 \%$ of pediatric patients had residual disease at the second look; almost all the recurrences occurred in the anterior epitympanum: in their technique they preserved the malleus handle, and this could make the reconstruction of the epitympanum more difficult. In our technique, if the ossicular chain has to be interrupted and/or removed, the malleus is completely removed and this allows an easier and more stable reconstruction of the anterior epitympanum. Moreover, as already described by Querat et al [10], hearing results do not depend from the preservation of the malleus. Also, leaving the handle of the malleus in place could prevent from an adequate cleaning of the supratubal recess with the possibility of leaving residual disease in this region. 
In 2005 DeRowe et al [4] wrote about 53 children treated with atticotomy without epitympanic reconstruction with $19 \%$ of recurrent/residual disease that needed a revision surgery with a CWD mastoidectomy. Penning et al [11] in 2009 published a report on 26 patients (17 adults, 9 children) operated for cholesteatoma removal through postauricular atticotomy with reconstruction of the scutum with cymbal cartilage: The results were $42 \%$ of recurrent/residual disease, and the authors highly recommend a second look after this procedure. This high rate of recurrence/residual is probably due to the fact that the authors preserved the ossicular chain even in case of the spread of the cholesteatoma medial to it. In our series, if this situation occurred, we removed the malleus and the incus even in case of intact ossicular chain. Our functional results indicate that this doesn't interfere with the hearing results if the ossiculoplasty is performed during the same procedure.

More recently the endoscopic approach has been used for the surgical management of limited attic cholesteatoma by Tarabichi in 2004 [5]. He used a fully endoscopic procedure with atticotomy, and reconstruction with a composite tragal graft in 69 patients (adults and children) and he was able to preserve the ossicular chain in $35 \%$ of them. The recurrence rate was 7\% and he found 1 residual during a revision surgery for ossiculoplasty. In 2011 Marchioni et $\mathrm{al}^{5}$ succeeded to preserve an intact ossicular chain using a fully endoscopic trans-canal atticotomy in 13 of 26 cases with 2 recurrences and 1 residual.

Beside these conservative techniques, Sanna et al [12], published their results about the modified Bondy's technique for the management of epitympanic cholesteatoma with intact pars tensa and intact ossicular chain. Even in case of involvement of the cholesteatoma medial to the ossicular chain, they succeeded to manage 230 cases preserving the chain and getting no recurrence and $7.4 \%$ of residual. Nonetheless, $3 \%$ of patients experienced ear discharge and no investigation was done about the other cavity-related issues. 
Our retrospective study indicates that the TA combines both the advantage of CWU and CWD procedures; indeed the rate of residual/recurrent disease is similar to the open technique without the drawback of the cavity. Furthermore all surgeries were performed in a single stage and there was no need of a second look since an imaging study was realized for detection of residual disease. Regarding the recurrent disease, this is related to the stability of the attical reconstruction; in case of an intact ossicular chain preserved after cholesteatoma removal this stability is guaranteed by the ossicular chain itself if the fascia and the cartilage are posed over the malleus handle. On the contrary, in case of ossicular chain disruption, both malleus and incus should be removed in order to stabilize the attical reconstruction over the ossicular prosthesis.

In our department this technique has been used as the unique technique in $11 \%$ of all primary cholesteatoma cases operated in a 7 years period of time from 2007 to 2014. Cholesteatoma surgery is not exclusively relegated to tertiary referral center in our country, so limited cholesteatomas are widely operated anywhere. This could be a bias when interpreting the prevalence of this technique in our series. Moreover, in our tertiary referral center only adult patients can be treated: the majority of the few reports concerning this technique present in literature consider also pediatric patients.

Of course, the trans-canal atticotomy can be associated with a CWU mastoidectomy if there is a posterior extension of the cholesteatoma that is not controlled by the atticotomy itself $[13,14]$; or with a CWD mastoidectomy with mastoid obliteration in case of extensive disease or anatomical conditions that prevent from a safe and extensive removal of the pathology.

In conclusion, the TA represents a safe and effective surgical option for limited epitympanic/mesotympanic cholesteatoma with very low morbidity and rate of 
recurrent/residual diseases, and acceptable hearing results. It needs a radiological follow-up for detecting residual disease. 


\section{REFERENCES}

1. Sanna M, Facharzt AAL, Russo A, Lauda L, Pasanisi E, Bacciu A. (2009) Modified Bondy's technique: refinements of the surgical technique and long-term results. Otol Neurotol. 30:64-69.

2. Donald P, McCabe BF, Loevy SS. (1974) Atticotomy: a neglected otosurgical technique. Ann Otol Rhinol Laryngol. 83:652-662.

3. Gaillardin L, Lescanne E, Morinière S, Robier A. (2012) Canal wall up tympanoplasty for middle ear cholesteatoma in adults: modeling cartilage. Eur Ann Otorhinolaryngol Head Neck Dis. 129:82-86.

4. DeRowe A, Stein G, Fishman G, et al. (2005) Long-term outcome of atticotomy for cholesteatoma in children. Otol Neurotol. 26:472-475.

5. Tarabichi M. Endoscopic management of limited attic cholesteatoma. (2004) Laryngoscope. 114:1157-1162.

6. Marchioni D, Alicandri-Ciufelli M, Molteni G, Villari D, Monzani D, Presutti L. (2011) Ossicular chain preservation after exclusive endoscopic transcanal tympanoplasty: preliminary experience. Otol Neurotol. 32:626-631.

7. Wullstein SR. (1974) Osteoplastic epitympanotomy. Ann Otol Rhinol Laryngol. 83:663-669.

8. East DM. (1998) Atticotomy with reconstruction for limited cholesteatoma. Clin Otolaryngol Allied Sci. 23:248-252. 
9. Duckert LG, Makielski KH, Helms J. (2002) Management of anterior epitympanic cholesteatoma: expectations after epitympanic approach and canal wall reconstruction. Otol Neurotol. 23:8-13.

10. Quérat C, Martin C, Prades J-M, Richard C. (2014) Canal wall up tympanoplasty for cholesteatoma with intact stapes. Comparison of hearing results between cartilage and PORP on stapes and impact of malleus removal and total reinforcement of the tympanic membrane by cartilage. Eur Ann Otorhinolaryngol Head Neck Dis. 131:211216.

11. Pennings RJE, Cremers CWRJ. (2009) Postauricular approach atticotomy: a modified closed technique with reconstruction of the scutum with cymbal cartilage. Ann Otol Rhinol Laryngol. 118:199-204.

12. Sanna M, Duong TM. (2012) Ossicular chain preservation in epitympanic cholesteatoma surgery: the modified Bondy technique. Otol Neurotol. 33:278; author reply $278-279$.

13. Rondini-Gilli E, Mosnier I, Julien N, et al. (2001) [One-stage surgery of middle ear cholesteatoma in adults: apropos of 180 cases]. Rev Laryngol Otol Rhinol (Bord). $122: 75-79$.

14. Rondini-Gilli E, Grayeli AB, Borges Crosara PFT, et al. (2003) Ossiculoplasty with total hydroxylapatite prostheses anatomical and functional outcomes. Otol Neurotol. 24:543-547. 
The authors have no financial disclosure of conflicts of interest to declare. 
Table 1. Details of the population. ABG: air-bone gap; FU: follow-up

\begin{tabular}{|c|c|c|c|c|c|c|c|c|}
\hline PATIENT & AGE & $\begin{array}{l}\text { preoperative } \\
\text { ABG (dB) }\end{array}$ & $\begin{array}{l}\text { Tympanoplasty } \\
\text { type }\end{array}$ & $\begin{array}{l}\text { Postoperative } \\
\text { otoscopy }\end{array}$ & $\begin{array}{l}\text { Postoperative } \\
\text { ABG (dB) }\end{array}$ & $\begin{array}{l}\text { CT scan } \\
\text { (opacity) }\end{array}$ & $\begin{array}{l}\text { MRI (residual } \\
\text { cholesteatoma) }\end{array}$ & $\begin{array}{l}\text { FU } \\
\text { (Months) }\end{array}$ \\
\hline 1 & 51 & 13,125 & 2 & Well-healed & 16,25 & Yes & No & 49 \\
\hline 2 & 43 & 17,5 & 2 & Well-healed & 10 & No & & 21 \\
\hline 3 & 71 & 33,75 & 2 & Well-healed & 11,25 & No & & 19 \\
\hline 4 & 33 & 15 & 2 & Well-healed & 5 & Yes & No & 30 \\
\hline 5 & 25 & 11,875 & 3 & Well-healed & 16,25 & No & & 54 \\
\hline 6 & 17 & 30 & 3 & Well-healed & 6,875 & No & & 51 \\
\hline 7 & 37 & 8,75 & 1 & Well-healed & 0 & No & & 17 \\
\hline 8 & 72 & 38,125 & 3 & Well-healed & 5 & No & & 27 \\
\hline 9 & 54 & 20,625 & 3 & Well-healed & 5 & No & & 13 \\
\hline 10 & 36 & 6,25 & 2 & Well-healed & 0 & Yes & No & 44 \\
\hline 11 & 62 & 21,875 & 1 & Well-healed & 10 & No & & 26 \\
\hline 12 & 47 & 11,25 & 2 & Well-healed & 5 & No & & 13 \\
\hline 13 & 48 & 13,125 & 2 & Well-healed & 11,875 & No & & 24 \\
\hline 14 & 29 & 33,125 & 3 & Well-healed & 6,25 & No & & 32 \\
\hline 15 & 61 & 21,25 & 2 & Well-healed & 7,5 & No & & 18 \\
\hline 16 & 32 & 43,125 & 3 & Well-healed & 21,25 & No & & 15 \\
\hline 17 & 65 & 9,375 & 1 & Well-healed & 8,75 & No & & 18 \\
\hline 18 & 60 & 17,5 & 3 & Well-healed & 12,5 & No & & 16 \\
\hline 19 & 28 & 23,75 & 3 & Well-healed & 25 & No & & 24 \\
\hline 20 & 63 & 5 & 2 & Well-healed & 8,75 & No & & 14 \\
\hline 21 & 42 & 45 & 2 & Well-healed & 3,75 & No & & 16 \\
\hline 22 & 21 & 15 & 2 & Well-healed & 17,5 & Yes & No & 21 \\
\hline 23 & 68 & 2,5 & 2 & Well-healed & 6,25 & No & & 16 \\
\hline 24 & 30 & 5 & 2 & Well-healed & 5 & No & & 14 \\
\hline 25 & 51 & 6,25 & 2 & $\begin{array}{l}\text { Cartilage } \\
\text { retraction }\end{array}$ & 11,25 & No & & 13 \\
\hline 26 & 36 & 35 & 2 & Well-healed & 31,25 & No & & 14 \\
\hline 27 & 44 & 15 & 1 & Well-healed & 5 & No & & 26 \\
\hline
\end{tabular}


Table 2. Audiological results. Patients are divided depending on the ossicular chain reconstruction; Type 1: intact ossicular chain, no ossicular chain reconstruction; Type 2: ossicular reconstruction with partial prosthesis; Type 3: ossicular reconstruction with total prosthesis. AC: air-conductive; BC: bone-conductive; PTA (pure tone average). ABG: airbone gap. Results are expressed by the mean \pm SD

\begin{tabular}{|l|l|l|l|l|l|l|l|}
\hline $\begin{array}{c}\text { Ossicular } \\
\text { chain } \\
\text { reconstruction }\end{array}$ & $\mathrm{N}$ & $\begin{array}{c}\text { Preoperative } \\
\text { AC PTA }(\mathrm{dB})\end{array}$ & $\begin{array}{c}\text { Preoperative } \\
\text { BC PTA }(\mathrm{dB})\end{array}$ & $\begin{array}{c}\text { Preoperative } \\
\text { ABG }(\mathrm{dB})\end{array}$ & $\begin{array}{c}\text { Postoperative } \\
\text { AC PTA } \\
(\mathrm{dB})\end{array}$ & $\begin{array}{c}\text { Postoperativ } \\
\text { e BC PTA } \\
(\mathrm{dB})\end{array}$ & $\begin{array}{c}\text { Postoperative } \\
\text { ABG }(\mathrm{dB})\end{array}$ \\
\hline Type 1 & 4 & $26 \pm 8.5$ & $12 \pm 5.5$ & $14 \pm 6.1$ & $22 \pm 6.5$ & $16 \pm 4.2$ & $6 \pm 4.4$ \\
\hline Type 2 & 15 & $37 \pm 17.7$ & $21 \pm 9.4$ & $16 \pm 12.5$ & $34 \pm 18$ & $24 \pm 15.3$ & $10 \pm 7.5$ \\
\hline Type 3 & 8 & $46 \pm 11$ & $19 \pm 7.5$ & $27 \pm 10.6$ & $32 \pm 4.3$ & $18 \pm 8.1$ & $13 \pm 7.8$ \\
\hline
\end{tabular}


Fig1 Surgical view of the left ear. Inferior (1 white star) and superior (2 white stars) incisions of the external auditory canal. Black arrows show an epitympanic cholesteatoma

Fig2 Surgical view of a right ear undergoing trans-canal atticotomy for epitympanic cholesteatoma extending to the retrotympanum. The tympano-meatal flap has been detached from the malleus handle (black arrow) and the epitympanic cholesteatoma pocket is isolated (white arrow). Mesotympanic extension of the cholesteatoma is seen (black star) behind an intact chorda tympani nerve (white star)

Fig3 Examples of CT-scan of patients included in the study: Left CT-scan image showing an epitympanic cholesteatoma involving the retrotympanum (a); limited lateral epitympanic cholesteatoma (b); Medial extension to the ossicular chain of an epitympanic cholesteatoma (c)

Fig4 Surgical view of a left ear after cholesteatoma removal. The $30^{\circ} 4 \mathrm{~mm}$ endoscope is used to check the completeness of the removal in the aditus ad antrum and retro-tympanum.

Fig5 Post-operative coronal CT-scan showing a well-aerated middle ear without any suspect opacity. In these cases MRI was not performed. 

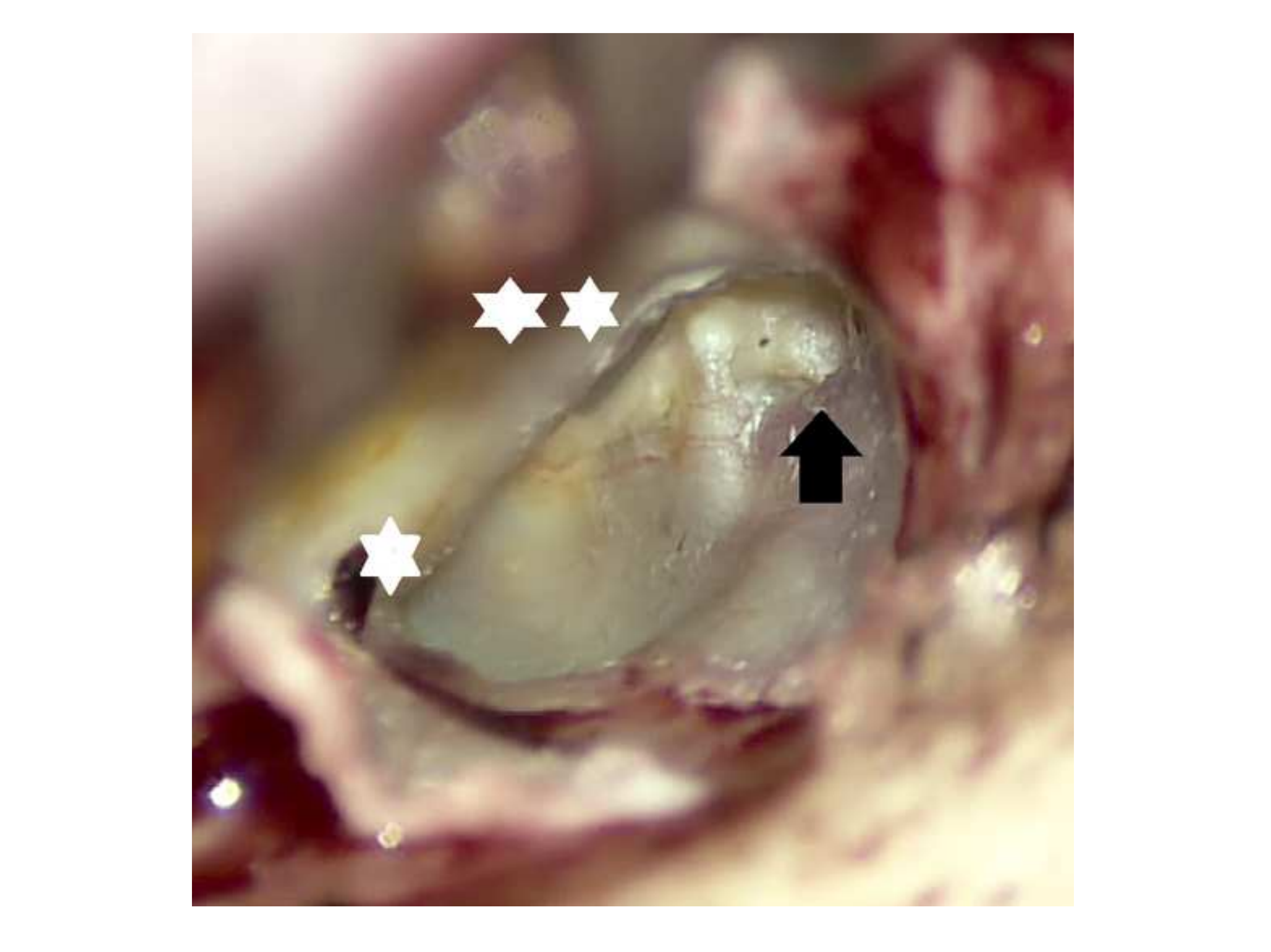

.
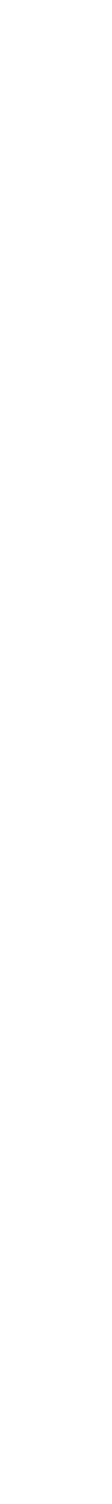

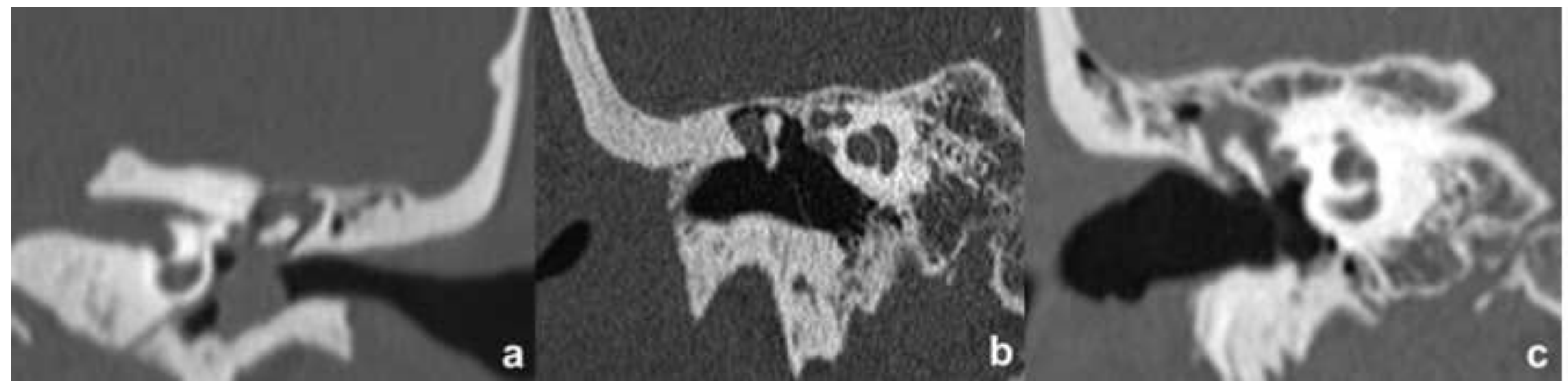

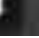

b 
Click here to download Figure Fig. 4.tif $\underline{\underline{ }}$
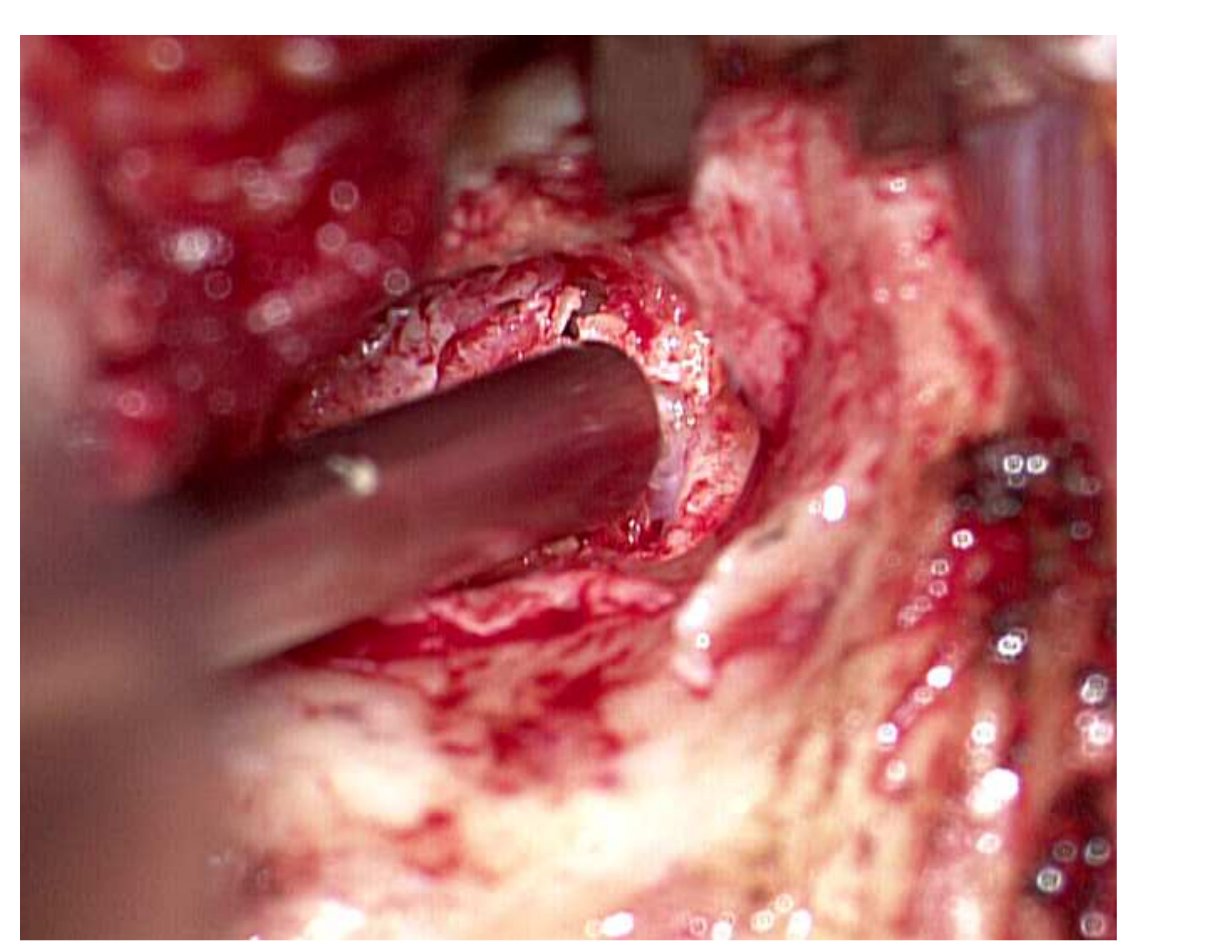

.
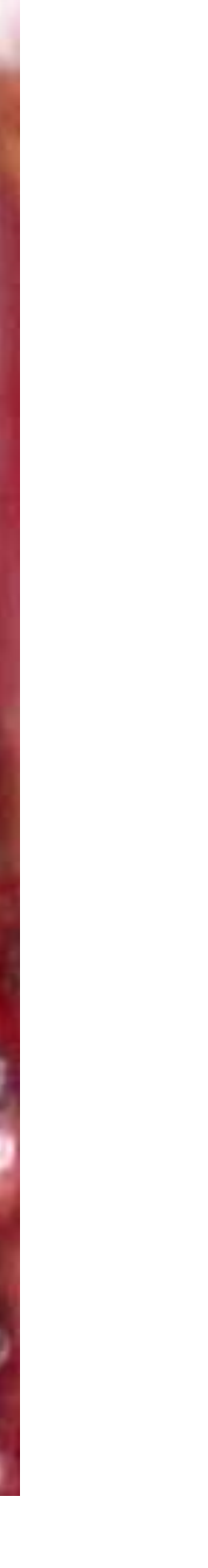
